\title{
sciendo
}

\section{Caffeine Produces Neutral Effects on Extraverts' and Introverts' Performance of Fundamental Motor Skills}

\author{
by \\ Ana Carolina Gomes ${ }^{1}$, Laura Tosini ${ }^{1}$, Dalton Oliveira ${ }^{1}$, Guilherme Lage ${ }^{2}$, \\ Emerson Franchini ${ }^{3}$, Cassio Meira Jr ${ }^{1}$
}

\begin{abstract}
Extraverts are active and talkative, while introverts are quiet and calm. This difference has been attributed to the cortical activation level (arousal), which is low in extraverts and high in introverts. Thus, to reach an optimal level of arousal, extraverts seek stimulation and introverts avoid it. As caffeine increases arousal levels, our primary aim was to investigate the effect of caffeine on the performance of extraverted and introverted university students in the execution of stability, manipulative, and locomotor tasks. Considering the above, we evaluated side effects, such as restlessness and trembling of hands, we also analyzed the individual's perception regarding caffeine intake and the placebo. Forty two volunteers were classified as 21 extraverts and 21 introverts by the Eysenck Personality Questionnaire. Participants performed three tasks on two different days, having previously ingested caffeine and a placebo in counterbalanced order. A double-blind technique was employed. The dependent variable was the execution time to perform the tasks. The analyses of variance [2 (extraversion/introversion) $x 2$ (caffeine $x$ placebo)] for each task did not show significant differences. Regarding the secondary aim, the chi-square test showed that introverts had a better perception of the substance they had ingested than did extraverts. Our findings indicate that in the execution of stability, manipulative, and locomotor tasks, either caffeine or the placebo produced the same effect, regardless of the participants' extraversion score. In addition, introverts were more sensitive to perceive which substance was ingested, caffeine or the placebo, than extraverts.
\end{abstract}

Key words: personality, coffee, motor control, motor skills.

\section{Introduction}

Personality is a concept that considers people in their totality, as individuals and complex beings (Eysenck, 2017; John et al., 2010; Weinberg and Gould, 2018), because it takes into account the inherited and acquired character, temperament, and intellect. Personality traits are relatively stable, long-lasting, and represent tendencies or predispositions to feel, behave, act, and think in a certain way in a variety of situations (Eysenck, 2017; Flores-Mendoza and Colom, 2006). Personality theories recognize that the individual's internal factors and the surrounding environment are determinants for behavior (John et al., 2010). The concept of the trait presupposes that the individual carries with her/him all traces, but with varying degrees of significance and generality, that is, a trait is not necessarily expressed in all situations of the everyday life, yet it is considered consistent to characterize people in most of their time (Eysenck, 2017; John et al., 2010; Weinberg and Gould, 2018). The focus of the present work is on the extraversion trait, which is related to how active, communicative, and assertive people are. Knowledge about this trait has been pointed out

\footnotetext{
1 - University of Sao Paulo - School of Arts, Science and Humanities, Sao Paulo - Brazil.

2 - Federal University of Minas Gerais - School of Physical Education, Physiotherapy and Occupational Therapy, Belo Horizonte Brazil.

3 - University of Sao Paulo - School of Physical Education and Sport, Sao Paulo - Brazil
} 
as an important tool to understand motor behavior of individuals so that to adjust pedagogical procedures regarding speed-accuracy tradeoff (Meira et al., 2018), practice schedule (Meira et al., 2015), and feedback provision (Kaefer et al., 2014).

Individual differences associated with extraversion reflect contrasts in the neurophysiological functioning, specifically cortical activation (arousal), which is the energy required for basic cortical processes to occur, such as perception, memory, and reasoning. Extraverts are typically sociable and talkative because they bear low levels of cortical activation. Introverts, in turn, have predispositions to be quiet and withdrawn due to their high levels of arousal (Eysenck, 2017; Flores-Mendoza and Colom, 2006). For these particular characteristics, extraverts tend to seek high-intensity stimuli, whereas introverts prefer lower intensity ones. The level of arousal is influenced by the environment and other external factors (FloresMendoza and Colom, 2008; Liguori et al., 1999; Meira et al., 2015, 2018; John et al., 2010), thereby extremely high or low arousal levels may provoke discomfort. This pattern has been explained by the inverted- $U$ principle: extraverts are infraactivated, thus they seek stimulating factors to achieve pleasant cortical activation levels, while introverts are hyper-activated and, as a result, they tend to select places or situations to reduce arousal to the optimal level (Flores-Mendoza and Colom, 2008; Liguori et al., 1999; Pervin et al., 2010; Weinberg and Gould, 2018). These extreme levels of arousal might lead extraverts and introverts to have different reactions to the same stimuli or situation. For example, extraverts tend to prefer speed over accuracy, while introverts are more inclined to accuracy over speed (Meira et al., 2018; Sawyer et al., 1982; Wakefield, 1979).

Caffeine has been shown to be capable of increasing arousal for both extraverts and introverts (Doyle et al., 2016). Thus, caffeine intake seems to potentiate extraverts to reach the optimal point of performance (Smith, 2014), but it may lead introverts to become even more hyperactivated, leading to a potential drastic decrease in performance (Nehlig et al., 1992; Smillie and Gökçen, 2010). Caffeine is the most consumed stimulant in the world (Annunciato et al., 2009) and reaches its peak in the bloodstream between
20 and $100 \mathrm{~min}$ after ingestion (Goldstein et al., 2010; Sawyer et al., 1982). It is known to show positive results in arousal alteration, given the change in the activation area (e.g. the prefrontal cortex, initiated by the change in the reticular activation). Consequently, due to caffeine intake, psychological and physiological behaviors might change, for instance, mood swings and an increased heart rate (Eysenck, 2017; Liguori et al., 1999; Smillie and Gökçen, 2010). Smith (2014) found enhanced working memory performance in extraverts after caffeine intake, when compared to introverts. Smillie and Gökçen (2010) examined the effects of ingesting $200 \mathrm{mg}$ of caffeine and a placebo in extraverted and introverted adults, who were instructed to respond "target" or "nontarget" on a standard keyboard; the task was performed in three consecutive blocks of 20 targets and 40 non-targets and the study confirmed the hypothesis that extraverts would improve memory performance after caffeine ingestion. Liguori et al. (1999) investigated the effects of caffeine intake on task performance of extraverts and introverts who consumed a caffeine dosage of $4 \mathrm{mg} / \mathrm{kg}$ twice a day, divided in morning and afternoon shots; participants completed the Profile of Mood States, a battery of self-report visual analog scales and the Digit Symbol Substitution Test (DSST) $180 \mathrm{~min}$ after drinking caffeine; despite extraverts being more willing, no differences were detected in the performances of extraverts and introverts and the authors claimed that the dose of caffeine consumed was not sufficient to increase the individuals' level of arousal.

Several studies have investigated the intake of caffeine, irrespective of personality traits. Annunciato et al. (2009) investigated the supplementation of caffeine and a placebo in the performance of strength exercises with one maximum repetition in the flat bench press and leg press $45^{\circ}$ exercises; there were three test sessions performed in a 72-hour interval; sessions were randomly selected: A - no supplementation, B - a placebo, C - caffeine $(6 \mathrm{mg} / \mathrm{kg})$ supplementation; no differences were found between caffeine and placebo groups, suggesting that caffeine was ineffective in providing increases in maximum strength. Improvements in cycling time were detected by Brietzke et al. (2017) in a study with random and 
counterbalanced administration of caffeine, a placebo, and no supplementation; their findings indicated that caffeine and a placebo improved participants' performance in the tests, in comparison to the control group.

High doses of caffeine may lead individuals to deal with collateral effects, such as, trembling hands, insomnia, restless, nervousness, irritability, and anxiety nausea. These effects are commonly described after the intake of $10-15 \mathrm{mg} / \mathrm{kg}$ of caffeine (Barban et al., 2010). Given that the level of cortical activation in the introverted group is higher, and caffeine would possibly increase it even more, introverts would have a better perception of what substance was ingested, considering that these side effects would be more intense in this group in particularly. More interestingly, even in lower doses, caffeine may cause a considerable discomfort, especially in introverts, since it leads to high arousal levels (Flores-Mendoza and Colom, 2008; Liguori et al., 1999; John et al., 2010).

Several studies reported differences between introverts and extraverts in motor behavior. Meira et al. (2008) found that extraverted children committed fewer errors than introverted ones while performing a dartthrowing task. Kaefer et al. (2014) concluded that self-controlled practice enhanced learning of a key depressing task in introverts and extraverts. The same task was employed by Meira et al. (2015), who indicated that the contextual interference effect i.e., random practice which degraded acquisition performance compared to blocked practice, but enhanced subsequent retention and transfer performance, was more pronounced for introverts than extraverts. Meira et al. (2018) determined in a speed-accuracy tradeoff task that elderly introverts fell short of the target more often and committed more overall errors than the elderly extraverts.

Given that introverts, unlike extraverts, avoid excessive stimulation sources (Eysenck, 2017) and taking into account that caffeine might constitute a source of stimulation because it enhances working memory and motor functions (Mahdi et al., 2019), the aim of this study was to investigate how caffeine would influence motor performance of extraverts and introverts. Specifically, our primary objective was to examine the effect of caffeine intake on stability, manipulative, and locomotor performance of extraverted and introverted individuals. We expected that caffeine would potentiate extraverts' motor performance (longer stability time and shorter manipulative and locomotor times), when compared to introverts. As we used a doubleblind technique of substance administration, the secondary objective was to analyze the perception of the individuals with regard to the substance ingested i.e., caffeine or a placebo. Our expectation was that introverts would perceive more precisely which substance they ingested in comparison to extraverts.

\section{Methods}

\section{Participants}

The study had an intentional final sample of 42 (21 in each group) university students of both sexes, aged between 18 and 35 years (22.14 \pm 3.88 years). According to Santos (2017), in order to reach the final intentional sample proposed in this study, the sample estimate was that 144 students answered the EPQ. However, 186 questionnaires were applied to reach the proposed final intentional sample, exceeding the initial estimate of 144 people.

Participants were non-smokers and declared absence of any neuromuscular or cardiopulmonary disorder. None of the participants reported consuming caffeine in levels higher than $50 \mathrm{mg}$ per day. The mean score in the extraversion trait was $12 \pm 4$. Considering the division of the groups, the mean score was $16 \pm 1$ for extraverts and $8 \pm 2$ for introverts. The extraverted group was composed of 12 males and 9 females (age $21 \pm 3$ years) and the introverted group was also composed of 12 males and 9 females (age $22 \pm 4$ years). All participants declared no previous experience with the tasks.

The study was approved by the Ethics Committee of the university. We excluded from the sample any person with cognitive, physical or cardiac restriction that could affect performance of the experimental tasks or which presented a risk to the participants' health.

\section{Instruments and tasks}

In order to classify participants as extraverts and introverts, we used the EPQ, translated and validated to the Brazilian population under the name of "Questionário de personalidade de Eysenck" (Tarrier et al., 1980). 
The instrument evaluates extraversion, neuroticism, and psychoticism. The EPQ also provides a quantifiable control scale which detects falsification in the responses of the questionnaire. The extraversion range score varies from 0 to 18 points, therefore, for allocation to the experimental groups, it was necessary to obtain scores between 0-12 points for the introverted group and 14-18 points for the extraverted one. We excluded from the sample participants who scored 13 on extraversion or who scored above 12 on the control scale. These cut-off values were defined based on previous studies with similar samples from the same geographic region, according to which the average score in the extraversion trait was between 12 and 13 points (Kaefer et al., 2014; Meira et al., 2015, 2018). Owing to the principle of independence of traits (Eysenck, 2017; Flores-Mendoza and Colom, 2006), the other traits were not considered for the purposes of this study.

Participants performed three tasks: stability, manipulative, and locomotor. We chose these tasks to address the three main categories of fundamental motor skills (Gallahue et al., 2012). The stability task was performed with the subject in the upright position and trying to keep the stabilometer on the horizontal axis for as long as possible. Three 30-s trials were executed. The stabilometer is a platform which measures the balance skill (Lafayette Instrument, 2004). Performance in each trial was recorded using the device's own software, which captured the equilibrium time, besides that, the device was programmed to operate within a five-degree deviation to the left and to the right. The Minnesota Manual Dexterity Test which measures the levels of accuracy and control, was used as the manipulative task (Lafayette Instrument, 1998). The test measures how fast the individual places the 60 discs in the columns of four and rows of 15 holes of the board. After performing a familiarization trial, the participant executed two trials handling the discs with the dominant hand. The time of each trial was recorded with a stopwatch. The shuttle run test was employed as the locomotor task, the test consists of running 80 $\mathrm{m}$, as fast as possible, on a court with the predemarcated area of $20 \mathrm{~m}$, so that the person had to run $20 \mathrm{~m}$ from side to side, four times to complete the $80 \mathrm{~m}$ distance. There was a familiarization trial, and then the two main trials. The time of each trial was recorded with a stopwatch (Léger et al., 1988).

\section{Design and procedures}

The three tasks were performed under two different conditions (caffeine and a placebo), on two consecutive days. Substance ingestion occurred $30 \mathrm{~min}$ before the start of the experiment. The order of caffeine/placebo administration respected a counterbalancing technique, as it can be seen in Figure 1.

The double-blind method was used in the designation of conditions. A master student was responsible for this double-blind procedure. Only at the end of data analysis the author learned which symbol represented each substance. The order of accomplishment of the three tasks was also counterbalanced between participants. Within the same participant, the order of accomplishment of the three tasks was identical under both conditions. A one-minute interval was respected between the trials and knowledge of results was provided after the end of the trial.

Since caffeine ingestion improves overall performance (e.g. Doyle et al., 2016), our participants were instructed to restrict their caffeinated products intake within 24 hours prior to the execution of the tasks. Caffeine levels above $6 \mathrm{mg} / \mathrm{kg}$ may lead performance to decline (Goldstein et al., 2010), possibly because of hyperactivation, especially for individuals who already have high cortical activation (Doyle et al., 2016). Thereby, we adopted the dose of $5 \mathrm{mg} / \mathrm{kg}$. Caffeine and the placebo had similar appearance, thus avoiding sensory stimulation of smell or vision.

\section{Data analysis}

Regarding the primary objective, the variables of interest considered for analysis were the following: personal variable - extraverts $x$ introverts; experimental variable - caffeine $x$ placebo; observed variable - time to complete the task. An exploratory analysis of the variable observed was performed within each of the three tasks, followed by a descriptive analysis by groups and conditions. Subsequently, after checking for normality and homoscedasticity, for each task, a two-way factorial ANOVA with repeated measures was executed, per group: extraverts $\mathrm{x}$ introverts, and per condition: caffeine 
x placebo; the group variable was considered as between-subjects, while the condition variable was considered as within-subjects. Partial eta squared values $(\omega)$ were reported to indicate the magnitude of the effect for significant results. When necessary, the F statistics were adjusted for degrees of freedom. With respect to the secondary objective, the descriptive analysis involved the frequency of responses on the ingested substance, organized by the two groups. The frequencies were then compared inferentially by chi-square tests. The level of significance was set at $5 \%$.

\section{Results}

The exploratory analysis indicated no missing data, normality of the distributions, and absence of extreme outliers.
Table 1 shows the descriptive values of each task according to groups (extraverts $x$ introverts) and conditions (caffeine $\mathrm{x}$ placebo).

In Table 2, ANOVA variables are displayed for stability, manipulative, and locomotor tasks. No significant differences were found for condition and extraversion factors, nor the interaction extraversion $x$ condition.

Regarding the secondary objective, Table 3 presents chi-square statistical variables and frequencies of correct and wrong answers of the groups concerning the perception of caffeine and placebo intake. There were significant differences between yeses and noes in the group of introverts, however, no significant differences were detected for extraverts.

Table 1

Time of extraverts and introverts during stability, manipulative, and locomotor tasks

\begin{tabular}{cccc}
\hline Tasks & Condition & $\begin{array}{c}\text { Extraverts } \\
(\text { mean } \pm \text { SD })\end{array}$ & $\begin{array}{c}\text { Introverts } \\
(\text { mean } \pm \text { SD })\end{array}$ \\
\hline \multirow{2}{*}{ Stability } & Caffeine & $19.76 \pm 3.25$ & $18.42 \pm 3.91$ \\
& Placebo & $18.79 \pm 3.54$ & $18.11 \pm 4.31$ \\
Manipulative & Caffeine & $19.76 \pm 2.63$ & $19.96 \pm 1.92$ \\
& Placebo & $19.56 \pm 2.62$ & $19.89 \pm 2.17$ \\
& Caffeine & $75.30 \pm 7.86$ & $73.47 \pm 8.17$ \\
& Placebo & $76.31 \pm 10.45$ & $75.16 \pm 10.32$ \\
\hline
\end{tabular}

Table 2

Stability, manipulative, and locomotor tasks statistical values regarding condition factor, extraversion factor and the interaction extraversion $x$ condition

\begin{tabular}{|c|c|c|c|c|}
\hline & & Stability & Manipulative & Locomotor \\
\hline \multirow{3}{*}{ Condition } & $\mathrm{F}$ & 0.337 & 0.337 & 0.064 \\
\hline & $\mathrm{p}$ & 0.565 & 0.565 & 0.805 \\
\hline & $\omega$ & 0.009 & 0.009 & 0.002 \\
\hline \multirow{3}{*}{ Extraversion } & $\mathrm{F}$ & 0.956 & 0.308 & 0.336 \\
\hline & $\mathrm{p}$ & 0.334 & 0.582 & 0.566 \\
\hline & $\omega$ & 0.024 & 0.008 & 0.009 \\
\hline \multirow{3}{*}{ Extraversion X Condition } & $\mathrm{F}$ & 0.346 & 0.092 & 0.267 \\
\hline & $\mathrm{p}$ & 0.56 & 0.763 & 0.608 \\
\hline & $\omega$ & 0.009 & 0.002 & 0.007 \\
\hline
\end{tabular}




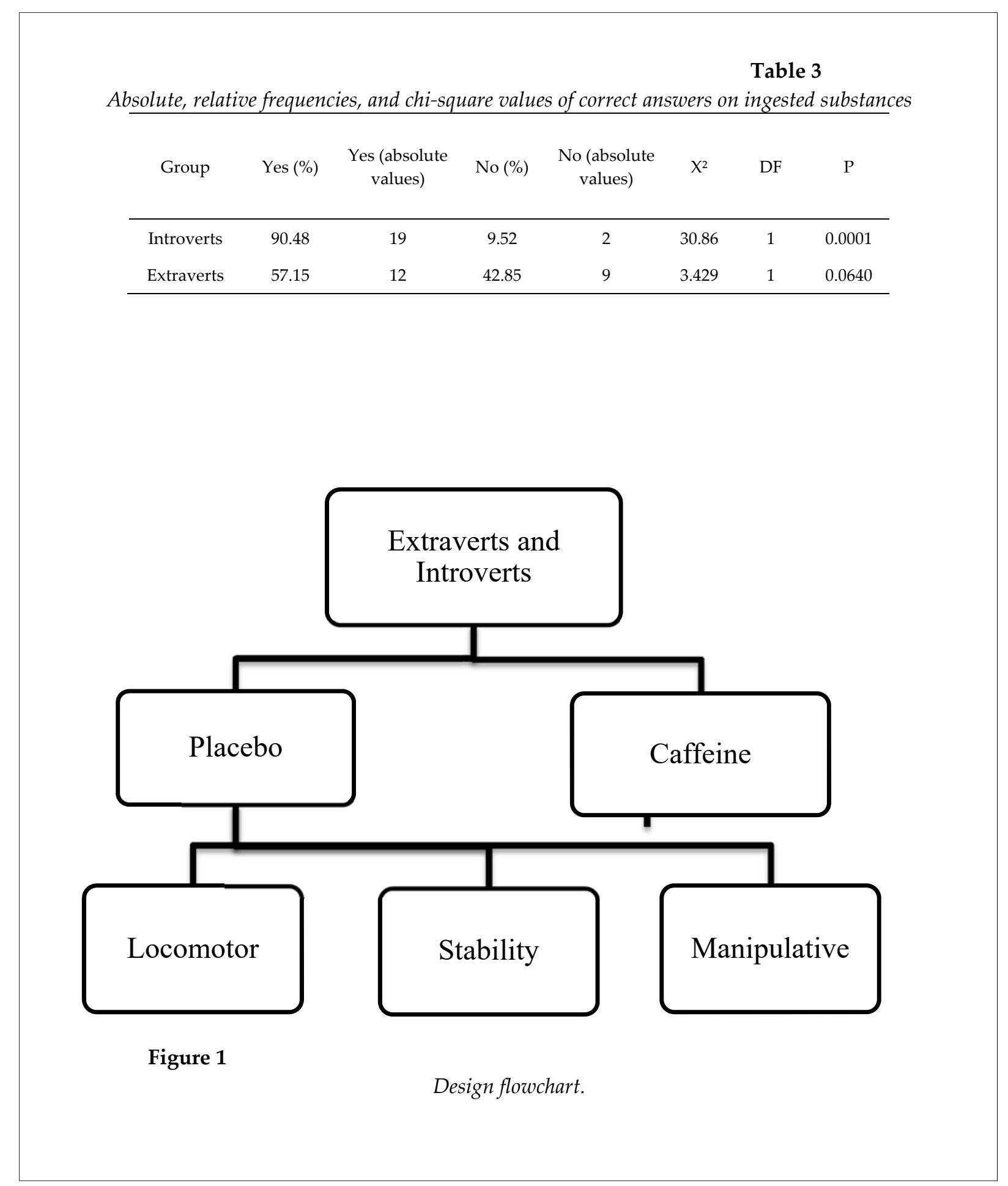

\section{Discussion}

Under both the caffeine and placebo conditions, the time values of extraverts and introverts were statistically similar in the three tasks. These findings corroborate previous studies by Amir et al. (2001) and Doyle et al. (2016). Amir et al. (2001) inspected the effects of two-day caffeine intake of $140 \mathrm{mg}$ in extraverted and introverted women. Although it was hypothesized that caffeine would improve surveillance performance of extraverts and impair introverts', there were no differences between the groups. Those authors claimed that the amount of caffeine was not sufficient to increase the participants' arousal. In turn, Doyle et al. (2016) found no significant difference regarding the 
accuracy of fencers who discontinued caffeinated products four days prior to testing, even with doses of $7.5 \mathrm{mg} / \mathrm{kg}$, which is $50 \%$ higher than the dose ingested by participants of the present study. Wilk et al. (2019) also indicated that high acute doses of caffeine, such as 9 and $11 \mathrm{mg} / \mathrm{kg}$, also did not improve muscle strength nor muscle endurance in athletes habituated to this substance. That may occur possibly because caffeine levels above $6 \mathrm{mg} / \mathrm{kg}$ may lead to hyper-activation, especially for individuals who already have high cortical activation (Doyle et al., 2016).

Also, a couple of studies have identified differences between extraverts and introverts with respect to caffeine intake. Smillie and Gökçen (2010) and Smith (2014) observed that caffeine intake enhanced performance of extraverts and hindered that of introverts. However, participants performed a sequence of three blocks in a discrete short-time task (N-Back) on a computer in the first study and several tasks of working memory in the second one.

Our findings are in line with the expectation that introverts would perceive more precisely which substance they ingested in comparison to extraverts. Introverted participants spontaneously reported feeling very agitated, trembling, de-concentrated during the experiment, even with some of them having reported trouble with sleeping after ingesting caffeine. Nehlig et al. (1992) accounted that caffeine intake induced increased levels of alertness and tremors, which affected performance. In the present study, these reactions were spontaneously declared by several participants by the end of the experiment. In contrast, our extraverted participants stated that on the very night they had ingested what they thought being caffeine, they felt either more focused and willing or not affected whatsoever. Also, some extraverts revealed feeling inattentive and tired after having ingested what they thought being the placebo. These reports are in agreement with the findings of Liguori et al. (1999), according to which the intake of $4 \mathrm{mg} / \mathrm{kg}$ caffeine increased vigor and disposition levels, yet cortical activation levels were not measured and no significant differences were identified between the performance of introverts and extraverts. Even though Sawyer et al. (1982) indicated that caffeine intake was related to mood, performance, and sensitivity, it had not yet been clearly determined how it affects accuracy, efficiency, endurance, and stress levels. The central nervous system does not appear to develop large tolerance for caffeine effects and, despite symptoms of dependence and withdrawal being reported, caffeine intake seems to improve endurance during repetitive task performance (Nehlig et al., 1992).

Our participants may not have benefited from caffeine action. It is known that caffeine potentially changes arousal levels and, as a result, performance levels of extraverts and introverts would differ. In this way, we conjectured that the findings could have been different if the tasks had been longer and more intense. We call for upcoming studies to investigate this issue. Also, due to the extremely uncomfortable arousal levels, introverts may have used compensatory strategies or processing alternatives to maintain task performance. The Attentional Control Theory (ACT) proposed by Eysenck et al. (2007) upholds that cognitive compensatory strategies take place when a facet of personality - anxiety is raised to extreme levels. In accordance with the ACT, the cognitive task performance of anxious individuals is similar to that of non-anxious ones because performance is offset by psychophysiological responses, such as increased cortical activation, physical and mental exertion, and observable symptoms, such as tremors, sweating, flushing, and an increased heart rate. Although formulated to explain differences in the context of anxiety, the ACT is a train of thought which could explain the findings of the present study, particularly for introverts, who, after caffeine ingestion, are theoretically driven to extreme uncomfortable cortical activation levels. Even under these arousal hyper-activation conditions, our introverts seemed to be capable of sustaining performance as a consequence of compensatory strategies (e.g. reported processing alternatives associated to increased physical and mental exertion, tremors, sweating, and agitation).

We recognize some limitations which were treated as rigorously as possible to minimize interference in the findings: (1) self-reported measurement of personality (EPQ); (2) although individuals were asked to abstain from caffeine in the 24 hours prior to testing, it was not possible to guarantee this caffeine withdrawal; (3) we did not measure psychophysiological variables, such as 
the heart rate, perceived exertion, and arousal levels; (4) although it was asked whether the volunteer had prior knowledge of any of the tasks, the participants' prior physical activity level was not measured.

\section{Conclusions}

Following either caffeine or placebo intake, the time to accomplish the stability, manipulative, and locomotor tasks was similar for extraverts and introverts.

Introverts were more sensitive to perceive the ingested substance - caffeine and placebo than extraverts.

\section{What Does This Article Add?}

This study extends the knowledge about the perspective of individual differences in caffeine and placebo offsets in extraverts and introverts performing fundamental motor skills. Either caffeine or placebo intake produced the same effects in stability, manipulative, and locomotor performance of extraverts and introverts. Our findings can help support decisions on the intake of a stimulant substance (caffeine) for extraverts and introverts within the scope of fundamental motor skills. Also, our findings report that introverts are more sensitive to perceive caffeine than extraverts.

\section{References}

Amir T, Alshibani F, Alghara T, Aldhari M, Alhassani A, Bahry G. Effects of caffeine on vigilance performance in introvert and extravert noncoffee drinkers. Social behavior and personality, 2001; 9(6): 17624

Annunciato R, Mello R, Faria T, Marcelino J, Navarro A. Acute caffeine supplementation related to increased strength. Rev Bras Nut Esp, 2009; 3(18): 508-517

Barban D, Pansardi G, Lacour AS, Navarro F. Metabolic changes caused by caffeine consumption in men between 20 and 35 years old. Rev Bras de Nut Esp, 2010; 4(22): 291-296

Beltrão N, Meira CM, Souza L, Cunha A, Cattuzzo M. Motor performance of extrovert and introvert children. Motricidade, 2012; 8: 993-998

Brietzke C, Asano R, Lima F, Pinheiro F, Alvarenga P, Ugrinowitsch C, Pires F. Caffeine effects on VO2MAX test outcomes investigated by a placebo perceived-as-caffeine design. Nut Health, 2017; 23(4): 231-238

Doyle TP, Lutz RS, Pellegrino JK, Sanders DJ, Arent SM. The effects of caffeine on arousal, response time, accuracy and performance in division I collegiate fencers. J Strength Cond Res, 2016; 30(11): 3228-3235

Eysenck HJ. The biological basis of personality. London: Routledge; 2017

Eysenck MW, Derakshan N, Santo R, Calvo MG. Anxiety and Cognitive Performance: Attentional Control Theory. Am Psychol Ass, 2007; 7(2): 336-353

Flores-Mendoza C, Colom R. Introduction to the psychology of individual differences. Porto Alegre: ArtMed; 2008

Gallahue DL, Ozmun JC Goodway J. Understanding Motor Development: infants, children, adolescents, adults. New York: McGraw-Hill. 7. ed.; 2012

Goldstein E, Ziegenfuss T, Kalman D, Kreider R, Campbell B, Wilborn C, Taylor L, Willoughby D, Stout J, Graves B, Wildman R, Ivy J, Spano M, Smith A, Antonio J. International society of sports nutrition position stand: caffeine and performance. J Int Soc Sports Nut, 2010; 7(8)

John OP, Robins R, Pervin L. Handbook of Personality: Theory and Research. London: The Guilford Press. 3. ed. 192-200; 2010

Kaefer A, Chiviacowsky S, Meira CM, Tani G. Self-Controlled Practice Enhances Motor Learning in Introverts and Extraverts. Res Q Exer Sport, 2014; 85: 226-233

Lafayette Instrument. The Complete Minnesota Dexterity Test: Examiner's Manual. Model 32023A. 1998. Available $\quad$ at: $\quad<$ https://meetinstrumentenzorg.blob.core.windows.net/testdocuments/Instrument141/141_2_N.pdf>; accessed: 17.05.2019

Lafayette Instrument. Stability Platform: Examiner's Manual. Model 16030. 2004. Available at: $<$ http://www.limef.com/Downloads/MAN127-16030-forpdf-rev3.pdf>; accessed: 17.05.2019 
Léger LA, Mercier D, Gadoury C, Lambert J. The multistage 20 metre shuttle run test for aerobic fitness. J Sport Sci, 1988; 6(2): 93-101

Liguori A, Grass JA, Hughes JR. Subjective effects of caffeine among introverts and extraverts in the morning and evening. Exp Cli Psychopharmacol, 1999; 7(3): 244-249

Meira CM, Fairbrother J, Perez CR. Contextual interference and introversion/extraversion in motor learning. Percept Motor Skills, 2015; 121(2): 447-460

Meira CM, Moraes R, Moura M, Ávila LTG, Tosini L, Magalhães FH. Extraversion/introversion and age related differences in speed accuracy tradeoff. Rev Bras Med Esp, 2018; 24(3): 225-229

Meira CM, Neiva JFO Effect of psychological traits on motor skill acquisition. In: Tani G. (Org.). Motor behavior: concepts, studies and applications. Rio de Janeiro: Guanabara Koogan, 163-174; 2016

Meira CM, Perez CR, Maia R, Neiva JF, Barrocal RM. Extraversion, neuroticism and motor performance in children performing the dart throwing. Rev Bras Psicol Esp, 2008; 2(2)

Nehlig A, Daval J, Debry G. Caffeine and the central nervous system: mechanisms of action, biochemical, metabolic and psychostimulant effects. Brain Res Reviews, 1992; 17: 139-170

Santos GEO. Cálculo amostral: calculadora on-line. 2017. Available at: <http://www.calculoamostral.vai.la>; accessed on 29.05.2017

Sawyer DA, Julia HL, Turin AC. Caffeine and human behavior: arousal, anxiety, and performance effects. J Behavioral Med, 1982; 5(4)

Smillie LD, Gökçen E. Caffeine enhances working memory for extraverts. Bio Psychol, 2010; 85: 496-498

Smith AP. Caffeine, extraversion and working memory. J Psychopharmacol, 2014; 27(1): 71-76

Tarrier N, Eysenck SBG, Eysenck HJ. National differences in personality: Brazil and England. Perso ind dif, 1980; 164-171

Valek M, Laslavic B, Laslavic Z. Daily caffeine intake among Osijek high school students: questionnaire study. Cro Med J, 2014; 45(1): 72-5

Wakefield JA. Using personality to individualize instruction. San Diego: Edits Publishers; 1979

Weinberg R, Gould D. Foundations of sport and exercise psychology. Miami: Human Kinetics. 7. ed.; 2018

Wilk M, Krzysztofik M, Filip A, Zajac A, Del Coso J. The effects of high doses of caffeine on maximal strength and muscular endurance in athletes habituated to caffeine. Nutrients. 2019; 15; 11(8): 1912

\section{Corresponding author:}

\section{Ana Carolina Gomes}

University of Sao Paulo - School of Arts, Science and Humanities

141 Nossa Senhora de Lourdes, Guarulhos, Sao Paulo, Brazil

+55 11910967681

E-mail address: ana3.gomes@alumni.usp.br 